\title{
Removal of textile dye Remazol Brilliant Blue Reactive (RBBR) using fibers of Citrullus lanatus (watermelon) and Cocos nucifera (green coconut) as adsorbent material
}

\author{
Melissa Dominique de Sousa Krueger' \\ Ana Carolina Volkmann" \\ Karine Thaise Rainert"II
}

\begin{abstract}
The accumulation of agro-industrial waste causes major environmental problems since most of these wastes are disposed of improperly. Among them, there are the watermelon (Citrullus lanatus) and the green coconut (Cocos nucifera), fruits of resistant and fibrous peels which are discarded in landfills because they are not widely used. Thus, the adsorption capacity of the Remazol Brilliant Blue Reactive (RBBR) dye was investigated using green coconut and watermelon residues as adsorbents. The combined effects of two independent variables ( $\mathrm{pH}$ and adsorbent mass) were evaluated using the response surface methodology. Under optimal conditions of acid $\mathrm{pH}$ and adsorbent mass of $1 \mathrm{~g}$, the dye removal efficiency reached values above $80 \%$ for both residues. The adsorption kinetics was described by the pseudo-second order model, while the equilibrium study was represented by the Freundlich isotherm for the watermelon residue and the Langmuir model for the green coconut. The results show that the agroindustrial residues of watermelon and green coconut could be effectively used to remove dye remazol brilliant blue reactive.
\end{abstract}

Keywords: Watermelon; Green coconut; Adsorption

\footnotetext{
I Student, Federal Institute of Science and Technology of Santa Catarina - IFSC, Jaraguá do Sul, Campus Center - SC, Brazil.

" Student, Federal Institute of Science and Technology of Santa Catarina - IFSC, Jaraguá do Sul, Campus Center - SC, Brazil.

II' Professor, Federal Institute of Science and Technology of Santa Catarina - IFSC, Jaraguá do Sul, Campus Center SC, Brazil.
} 


\section{Introduction}

Brazil is characterized by being the fifth largest textile producer in the world and the textile industries are the largest generators of liquid effluents which can contain a wide variety of dyes, acids, bases and oxidants, among others. Dyes in contact with the environment may present several risks to human health and to the aquatic ecosystem, such as death, delay in the regeneration of organisms and soil contamination. It is estimated that at least $30 \%$ of the dyes used in textile processing are lost to waste during the secondary processing stages (DALTIN, 1997). One of the major environmental problems faced by the textile sector today is related to the elimination of these wastewaters, so it is necessary to employ treatment techniques so that these substances can be discarded in receiving bodies without causing pollution or any kind of environmental impact (FURLAN, 2008).

The Remazol Brilliant Blue Reactive dye (RBBR) (Figure 1) presents in its composition compounds that belong to the family of polycyclic aromatic hydrocarbons (PAHs) which are formed by condensed aromatic rings. Due to its physicochemical properties and its large environmental distribution, the risk of human contamination by these substances is significant. In fact, because of their lipophilic character, PAHs and their derivatives can be absorbed by the skin, by ingestion or by inhalation, and are rapidly distributed throughout the body (ISAH et al, 2015).

Figure 1 - Molecular formula of RBBR dye

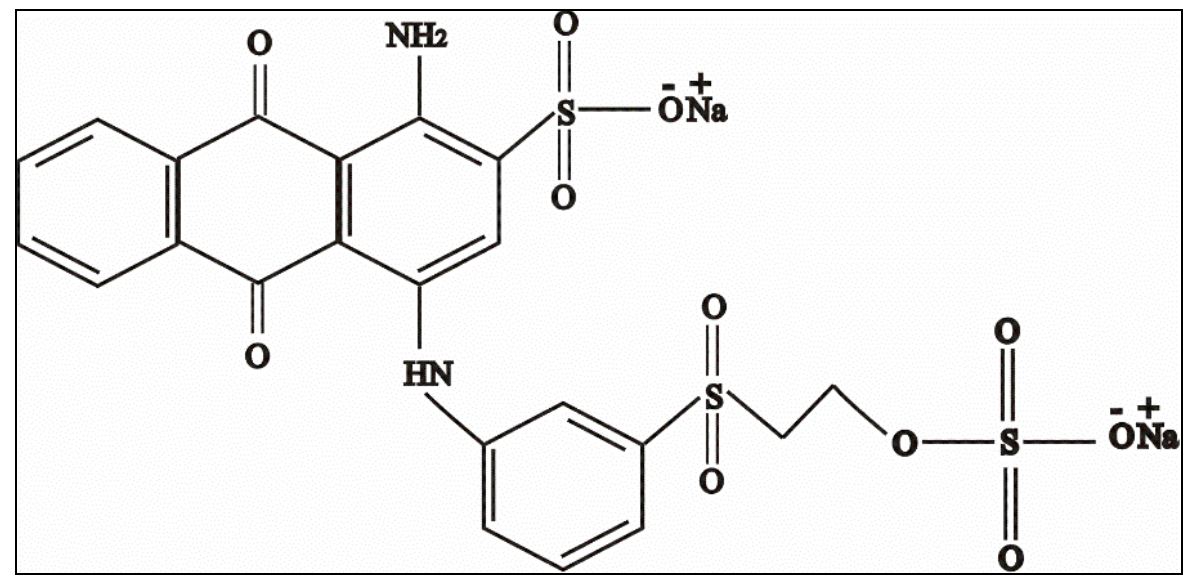


Regarding the removal of the color of this type of wastewater, several processes are used. Among them, there is the adsorption which is a process in which there is adhesion of particles of a fluid to a solid surface. The adsorption process is influenced by the adsorbent used and its variable characteristics, such as temperature, pressure and surface area of the adsorbent (FERNANDES et al., 2010). One of the most widely used adsorbents is activated carbon which can be used in several types of treatments having high efficiency. However, the problem has been its high cost of obtaining, so in some processes its use is impracticable. Agroindustrial residues can substitute for activated carbon and, as a result, there is the need to study alternative adsorbents which are available in large quantities and have a low cost. Is the case of the fruits of the green coconut and watermelon, which are characterized as fibrous, in addition to exist in abundance and produce large accumulation of organic waste (FERNANDES et al., 2010).

The watermelon endocarp is characterized as the pulp of the fruit. Due to the high consumption of this fruit, large amount of residues are generated, among them the pericarp and the mesocarp that constitute the fibrous fraction that can be used in the manufacture of biosorbent materials in the treatment of textile effluents (CORRADINI et al., 2009).

With the high consumption of green coconut juice, there is the generation of a lot of waste, being about $70 \%$ of the waste produced in the beaches of the Brazilian northeast composed of green coconut shells. The coconut fibers are obtained from the coconut mesocarp, being characterized by their hardness and durability attributed to the high lignin content (CORRADINI et al., 2009). Due to the greater amount of green coconut fibers, they are used efficiently as filters for wastewater treatment (ISAH et al, 2015).

Considering the large amount of residues generated by coconut and watermelon fruits, besides having a relative amount of fibers, the purpose of this study is to compare the effectiveness of coconut and watermelon fibers in the removal of RBBR textile dye. 


\section{Materials and methods}

The adsorbate used was produced in the laboratory, simulating a real textile effluent, with dye concentration at $50 \mathrm{mg} / \mathrm{L}$. To obtain the coconut fibers, the exocarp, the endocarp and the pulp were removed, resulting in the use of the fibrous mesocarp. Then, it was placed in the oven for 24 hours at $50{ }^{\circ} \mathrm{C}$ to remove all water in order to obtain the fiber. As for the watermelon fibers, the pericarp and the endocarp were removed, with the intention of using the mesocarp (white part) which was crushed and sieved to remove as much water as possible, and was subsequently taken to an oven in a period of 24 to 48 hours at $50^{\circ} \mathrm{C}$.

\subsection{Point of Zero Charge determination (PZC)}

To determine the point of zero charge, a $0.01 \mathrm{~mol} / \mathrm{L} \mathrm{NaCl}$ solution was used by varying the $\mathrm{pH}$ from 1 to 12, using $\mathrm{NaOH} 0.1 \mathrm{~mol} / \mathrm{L}$ and or $\mathrm{H}_{2} \mathrm{SO}_{4} 2 \mathrm{~mol} / \mathrm{L}$. Then, $10 \mathrm{~mL}$ of 0.01 $\mathrm{mol} / \mathrm{L} \mathrm{NaCl}$ were added to test tubes with different $\mathrm{pH}$ values and $30 \mathrm{mg}$ of watermelon and coconut were added to each of the tubes, while maintaining the same under stirring for 24 hours. After this time, the $\mathrm{pH}$ value was measured again. To determine the point of zero charge (when the $\Delta \mathrm{pH}$ of this solution is equal to zero), a graph was constructed from the value obtained with Equation 1 versus the initial $\mathrm{pH}$ value (AWUAL et al., 2014).

$\Delta \mathrm{pH}=(\mathrm{pH}$ final $-\mathrm{pH}$ initial $)$

\subsection{Preliminary adsorption tests}

The tests were performed in triplicate for 24 hours with $\mathrm{pH}$ variation in 2, 6 and 10 and mass $(g)$ in $0.5 ; 1.0$ and 1.5 on the adsorptive process in order to determine the best working conditions. The actual values of the levels of the variables studied are shown in Table 1. 
Table 1 - Variables and levels studied in 3k planning

\begin{tabular}{l|c|c|c}
\hline \multirow{2}{*}{ Variables } & \multicolumn{3}{|c}{ Levels } \\
\cline { 2 - 4 } & $\mathbf{( - 1 )}$ & 0 & $\mathbf{( + 1 )}$ \\
\hline $\mathrm{pH}\left(\mathrm{X}_{1}\right)$ & 2 & 6 & 10 \\
\hline $\begin{array}{l}\text { Adsorbent mass } \\
(\mathrm{g})\left(\mathrm{X}_{2}\right)\end{array}$ & 0.5 & 1 & 1.5 \\
\hline
\end{tabular}

The response used to determine the efficiency of dye removal was calculated by Equation 2.

$\%$ Removal $=\frac{\left(c_{0}-c_{t}\right)}{c_{n}} \times 100$

Where: $C_{0}$ is the initial concentration of the compound $(\mathrm{mg} / \mathrm{L})$ and $C_{t}$ is the concentration at time $\mathrm{t}(\mathrm{mg} / \mathrm{L})$. For the statistical analysis, the Statistica 7.0 program was used, applying the analysis of variance (ANOVA) and the response surface methodology, thus obtaining the dye removal efficiency with a second degree equation (Equation 3). This method is a multiple regression technique for adjusting a mathematical model of a set of experimental data (BAŞ; BOYACl, 2007).

$y=\beta_{0}+\beta_{1} X_{1}+\beta_{2} X_{2}+\beta_{12} X_{1} X_{2}+\beta_{11} X_{1}^{2}+\beta_{22} X_{2}^{2}+\varepsilon$

Where: $\beta_{0}$ is the intercession coefficient, $\beta_{1}$ and $\beta_{2}$ are linear coefficients, $\beta_{12}$ is interaction coefficients, $\beta_{11}$ and $\beta_{22}$ are quadratic coefficients and $X_{1}$ and $X_{2}$ are the independent variables used, respectively. To perform the tests, $250 \mathrm{~mL}$ Erlenmeyer flasks were used, containing $100 \mathrm{~mL}$ of the $50 \mathrm{mg} / \mathrm{L}$ dye solution using $\mathrm{NaOH}(0.1$ $\mathrm{mol} / \mathrm{L})$ and $\mathrm{H}_{2} \mathrm{SO}_{4}(2.0 \mathrm{~mol} / \mathrm{L})$ for $\mathrm{pH}$ adjustment. The tests were executed in the laboratory at room temperature $\left(25 \pm 2^{\circ} \mathrm{C}\right)$ under agitation. 


\subsection{Kinetics of Adsorption}

The Erlenmeyer containing $100 \mathrm{~mL}$ of dye solution $(50 \mathrm{mg} / \mathrm{L}$ ) were placed on a shaker table $(100 \mathrm{rpm})$ for a period of 24 hours, under the best conditions observed in the preliminary adsorption tests. Each flask was removed from at predetermined time intervals and the samples were then immediately filtered using a vacuum pump. The concentration of each sample was determined by reading the absorbance in a spectrophotometer at a wavelength of $590 \mathrm{~nm}$. Thus, the time required to achieve the equilibrium between the dye solution and the coconut and watermelon fibers was determined. The amount of adsorbate adsorbed at time $\mathrm{t}, \mathrm{q}_{\mathrm{t}}(\mathrm{mg} / \mathrm{g})$, was calculated through Equation 4.

$q_{t}=\frac{\left(c_{0}-c_{t}\right) * V}{m}$

Where: $q_{t}$ is the concentration of the adsorbate at time $t$ adsorbed on the adsorbent $(\mathrm{mg} / \mathrm{g}), \mathrm{C}_{0}$ is the initial concentration of the compound $(\mathrm{mg} / \mathrm{L}), \mathrm{Ct}$ is the concentration at time $\mathrm{t}$ in the solution $(\mathrm{mg} / \mathrm{L}), \mathrm{m}$ is the mass of the adsorbent $(\mathrm{g})$ and $\mathrm{V}$ is the volume of the solution (L). Finally, the kinetic data was analyzed using the pseudo-first and pseudo-second order models.

\subsection{Adsorption Isotherms}

The isotherms studies were similar to the adsorption kinetics studies. The experiments were conducted at $25^{\circ} \mathrm{C}$, for the time applied in the study on the kinetics contact at concentrations of $25-150 \mathrm{mg} / \mathrm{L}$. After reaching the equilibrium, the mixture was immediately filtered with vacuum pump. The final dye concentration of each sample was determined by reading the absorbance in a spectrophotometer at wavelength of $590 \mathrm{~nm}$. The amount of dye adsorbed by the adsorbent at equilibrium (qe) was calculated using Equation 4. The adsorption equilibrium was evaluated using the Langmuir and Freundlich isotherm models. 


\section{Results and Discussion}

\subsection{Point of Zero Charge (PZC) determination}

The electrical charges at the surface of the adsorbent and the influence of the $\mathrm{pH}$ are of great importance in the adsorption processes, once the adsorption happens as a function of the charges on the surface of the adsorbent, being able to decrease or increase the dye-adsorbent affinity. As the $\mathrm{pH}$ becomes lower than the point of zero charge (PZC), the surface region of the adsorbent is positively charged which assists in adsorption of dyes with anionic character. In contrast, when the surface is negatively charged, this favors the adsorption of dyes with cationic character (AWUAL et al., 2014).

Figures $2 \mathrm{~A}$ and $2 \mathrm{~B}$ indicate the $\mathrm{pH}$ variation as a function of the initial $\mathrm{pH}$ of the green coconut and the watermelon, respectively. Based on these data, the PZC of the adsorbent watermelon was estimated in 1 and of the green coconut in 3, so, below this value the adsorbent presents a positive surface charge favoring the adsorption of anions and above this value the surface is negatively charged, favoring the adsorption of cations.

Figure 2 - Determination of the point of zero charge (PZC) conjugated watermelon (A) and of green coconut (B) as a function of $\Delta \mathrm{pH}$ and initial $\mathrm{pH}$
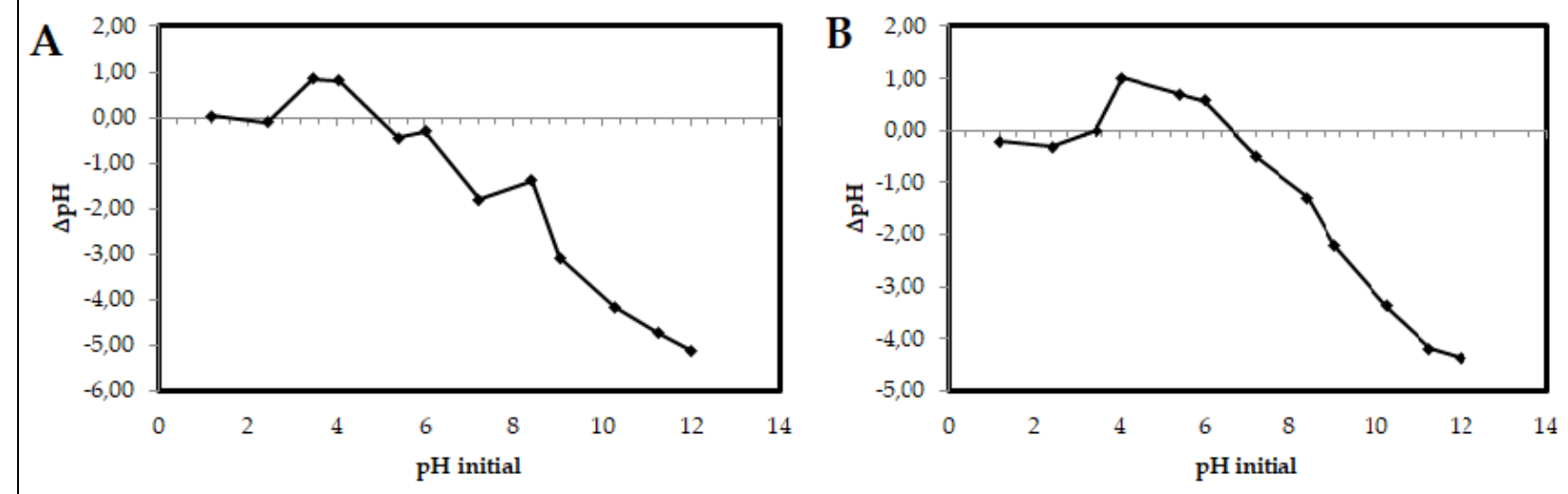

The RBBR dye contains numerous functional groups and the sulfonated one can be highlighted, which present negative charges in its environment (ISAH et al., 2015). 
Thus, the interaction of the dye on the surface of the adsorbent occurs through ionic interactions between positively charged groups of the adsorbent and negatively charged groups belonging to the adsorbate.

\subsection{Analysis of Variance (ANOVA)}

The analysis of variance (ANOVA) shows that out of the studied variables, the linear terms $X_{1}$ and $X_{2}$, the interaction term $X_{1}^{2} X_{2}$, and the square terms, $X_{1}$ and $X_{2}$, were significant on the response, having a value of $\mathrm{P}<0.05$ with a $95 \%$ confidence interval (Figures 3A and 3B). Thus, the linear and quadratic effects of all the individual variables studied, as well as the interactions of $\mathrm{pH}$ quadratic with the amount of adsorbent mass linear were statistically significant for both.

Figure 3 - Pareto diagram for the optimization of RBBR dye removal conditions with watermelon (A) and green coconut (B), quadratic terms (Q) and linear (L)

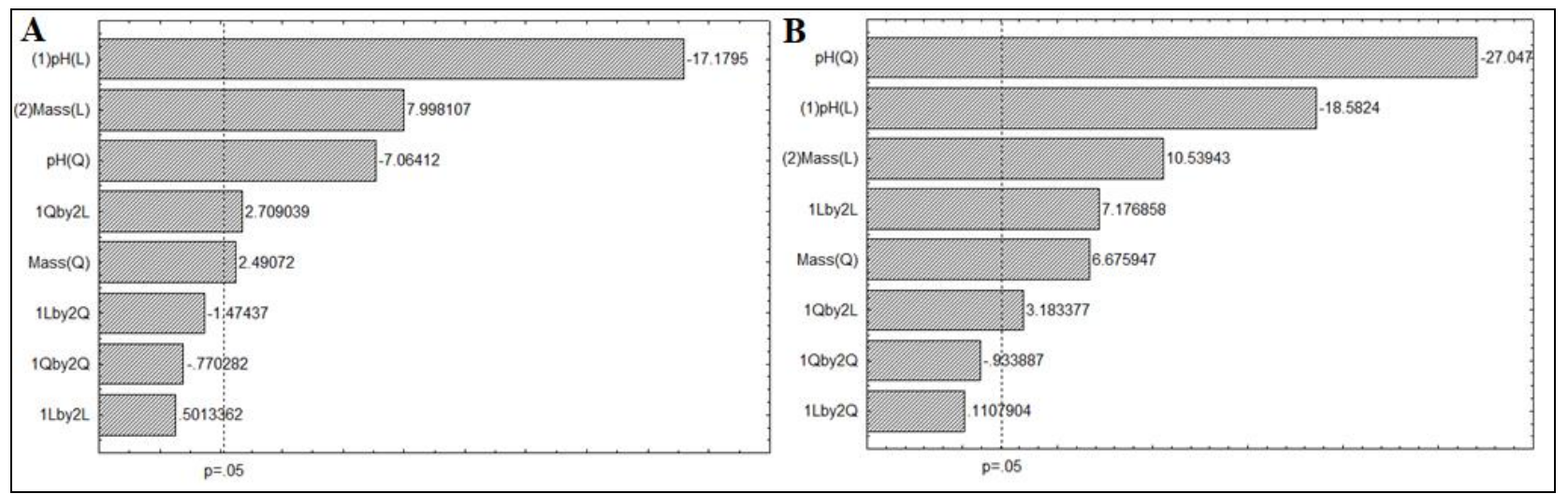

The effect of $\mathrm{pH}$ on the percentage of RBBR removal and its interaction with the amount of adsorbent is shown in Figure $4 \mathrm{~A}$ and $4 \mathrm{~B}$, in which it is observed that the best results obtained of the maximum RBBR removal reached were in the mass range $1 \mathrm{~g}$ and $\mathrm{pH} 2$ (acid) for the two adsorbents. 
Figure 4 - Three-dimensional effect of $\mathrm{pH}$ and adsorbent mass of watermelon $(\mathrm{A})$ and of green coconut (B) variables on RBBR dye removal

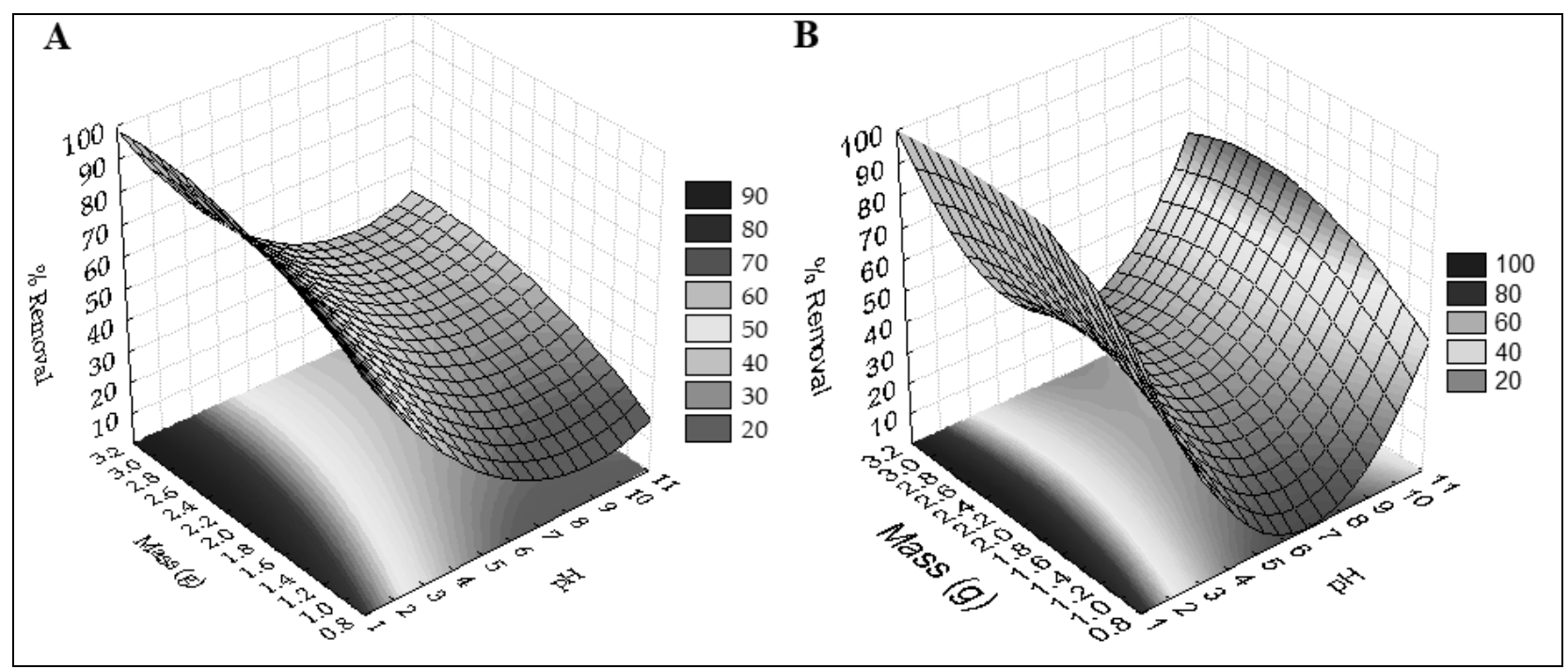

The quadratic polynomial equation (Equation 5) obtained by the response surface methodology for the \% Removal presented a high value of the determination coefficient $R^{2}(0.936)$ for the watermelon, showing that the model explains $93.6 \%$ of this process.

\%Removal $=69.33-18.13 X_{1}+32.02 X_{2}+1.01 X_{1}^{2}-5.67 X_{2}^{2}+31.17$

For the green coconut, the quadratic polynomial equation (Equation 6) obtained by the response surface methodology for the \% Removal presented a high value of the coefficient of determination R2 (0.972), showing that the model explains $97.2 \%$ of this process.

\%Removal $=99.79-35.60 X_{1}+35.14 X_{2}+1.77 X_{1} X_{2}+2.36 X_{1}^{2}-9.31 X_{2}^{2}+11.69$

The rapid increase in adsorbent mass adsorption is attributed to a larger surface area and availability of more active sites (DASTKHOON et al., 2015). Regarding the effect of $\mathrm{pH}$, this behavior can be explained because, under acidic conditions, the hydrogen atoms $\left(\mathrm{H}^{+}\right)$in solution tend to protonate the surface of the adsorbent (AWUAL et al., 2014). This comportment was also observed by Silva et al. (2016) who 
obtained a better adsorption of the RBBR dye at $\mathrm{pH} 2$. The variables with $\mathrm{pH} 10$ had a negligible adsorption. The model predicted the removal of 79\% RBBR in green coconut at $\mathrm{pH} 2$ of the RBBR dye solution, $1.0 \mathrm{~g}$ adsorbent, and for the watermelon 83\% of RBBR dye removal at $\mathrm{pH} 2$ and $1.0 \mathrm{~g}$ of adsorbent.

\subsection{Kinetics of Adsorption}

The adsorption kinetics was performed to verify the dynamics of the adsorption process. Analyzes were performed to verify the efficiency of the natural adsorbents coconut and watermelon in the adsorption of the RBBR dye at certain time intervals (Figure 5). The kinetic study is determined to establish the time required for the interaction between the adsorbent and the adsorbate in order to obtain the ideal time to have the contact of the dye with the fiber.

Figure 5 - Experimental adsorption kinetics of RBBR dye on coconut and watermelon adsorbents

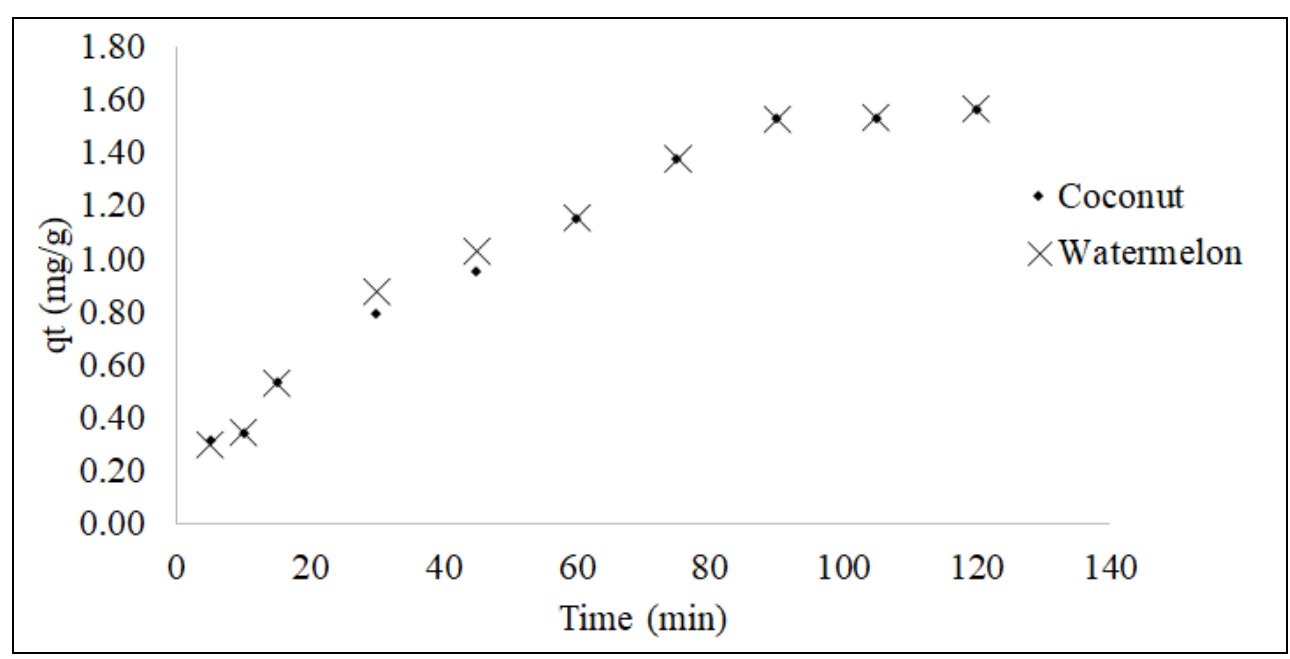

Initially, the adsorption of the RBBR dye was fast, in the second point, the values were superimposed for both, however, in the fourth and fifth measurements the watermelon adsorbed more. In terms of kinetics, it was observed that the interaction of the dye with the fiber in a period of 2 hours made the system achieved a chemical equilibrium in a time of 90 minutes for both adsorbent materials, presenting a fast kinetics. 
The equilibrium time reached is significantly lower than other similar materials used in the removal of RBBR dye, such as 10 hour cardboard paper chips (RAINERT, 2017) and orange peels with a time of 15 hours (MAFRA et al., 2013). In contrast, it is similar to the aqueous solution of bentonite with a time of 120 minutes (CHINOUNE et al, 2016).

The pseudo-first-order model assumes that the rate of adsorption of the solute over time is directly proportional to the difference between the amount adsorbed at equilibrium and the amount adsorbed at any time. The equation of pseudo-first order (HOSSEINI-BANDEGHARAEI et al., 2010) is represented by Equation (7).

$\log \left(q_{e}-q_{t}\right)=\log q_{e}-\frac{K_{1}}{2,303} t$

Where: $q_{t}$ and $q_{e}$ are the adsorbed amounts $(\mathrm{mg} / \mathrm{g})$ at time $\mathrm{t}$ and at equilibrium time, respectively, $\mathrm{t}$ is the adsorption time (minutes) and $\mathrm{K}_{1}$ is the adsorption rate constant (1/min). Representing $\log \left(q_{e}-q_{t}\right)$ versus $t$, it was possible to find the values of qe and $K_{1}$ (Figures $6 A$ and $6 B$ ). The values of $K_{1}, R^{2}$ (correlation coefficient) and qe are presented in Table 2.

The pseudo-second order model admits that the adsorption capacity is proportional to the number of active sites occupied in the adsorbent (UGURLU; KARAOGLU, 2011). This model is represented by Equation (8) (HO; MACKAY, 1999).

$$
\frac{1}{q_{t .}}=\frac{1}{K_{2} q_{e}^{2}}+\frac{1}{q_{e}} t
$$

Where: $\mathrm{K}_{2}$ is the adsorption rate constant (g/mg.min). The values of $\mathrm{q}_{e}$ and $\mathrm{K}_{2}$ can be determined from the slope and intercept of a linear graph of $t / q_{t}$ versus $t$ shown in figures 6C and 6D. The values of $K_{2}, R^{2}$ (correlation coefficient $q_{e}$ ) are given in Table 2 . The correlation coefficient was 0.999 and 0.982 for watermelon and green coconut respectively, as shown in Table 2 . It suggests a strong relationship between the parameters, indicating that the process follows pseudo-second order kinetics. The works of Isah et al. (2015) and Rainert et al. (2017) also obtained a pseudo-second 
order kinetics model for adsorption of the RBBR dye with coconut shell based activated carbon and SBS paperboard sheet respectively.

Table 2 - Kinetic parameters for RBBR adsorption in watermelon and green coconut

\begin{tabular}{|c|c|c|c|c|}
\hline \multirow[t]{2}{*}{ Kinetic Models } & \multicolumn{4}{|c|}{ Watermelon } \\
\hline & $q_{e, \exp }(m g / g)$ & $q_{e q}(\mathrm{mg} / \mathrm{g})$ & $\mathrm{K}_{1}(1 / \mathrm{min})$ & $\mathrm{R}^{2}$ \\
\hline \multirow[t]{2}{*}{ Pseudo-first order } & 1.566 & 0.29 & 0.038 & 0.95 \\
\hline & $q_{\text {eqExp }}(\mathrm{mg} / \mathrm{g})$ & $q_{e q}(\mathrm{mg} / \mathrm{g})$ & $\mathrm{K}_{2}(1 / \mathrm{min})$ & $\mathrm{R}^{2}$ \\
\hline \multirow[t]{3}{*}{ Pseudo-second order } & 1.566 & 2.311 & 0.008 & 0.99 \\
\hline & \multicolumn{4}{|c|}{ Green coconut } \\
\hline & $q_{e, \exp }(m g / g)$ & $\mathrm{q}_{\mathrm{eq}}(\mathrm{mg} / \mathrm{g})$ & $\mathrm{K}_{1}(1 / \mathrm{min})$ & $\mathrm{R}^{2}$ \\
\hline \multirow[t]{2}{*}{ Pseudo-first order } & 1.566 & 0.282 & 0.035 & 0.95 \\
\hline & $q_{\text {eqExp }}(\mathrm{mg} / \mathrm{g})$ & $q_{e q}(\mathrm{mg} / \mathrm{g})$ & $\mathrm{K}_{2}(1 / \mathrm{min})$ & $\mathrm{R}^{2}$ \\
\hline Pseudo-second order & 1.566 & 2.388 & 0.007 & 0.98 \\
\hline
\end{tabular}

Figure 6 - (A) kinetic model of pseudo-first order in watermelon; (B) kinetic model of pseudo-first order in green coconut; (C) kinetic model of pseudo-second order in watermelon; and (D) kinetic model of pseudo-second order in green coconut of the RBBR dye (50 mg/L)
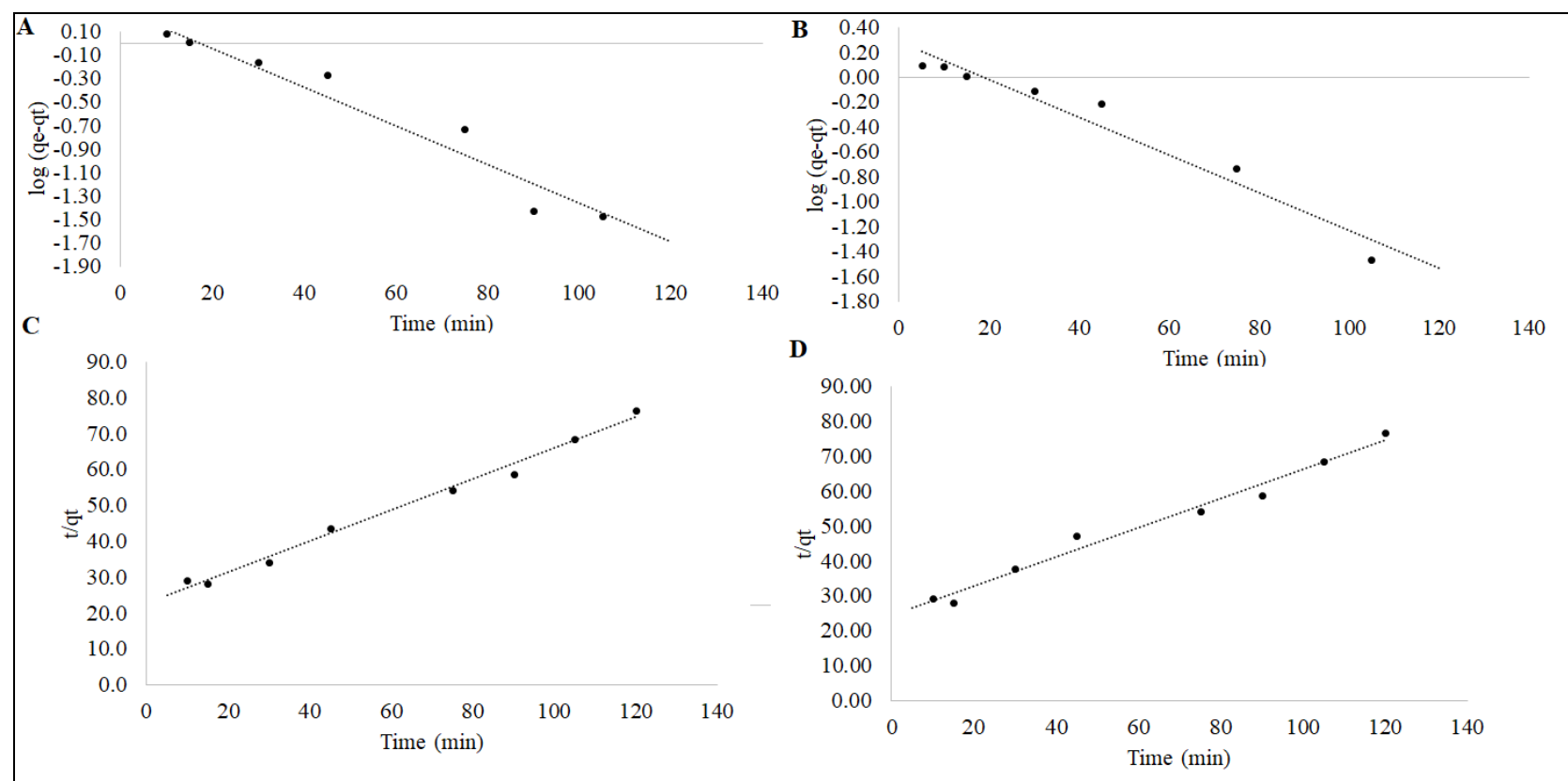


\subsection{Adsorption Isotherms}

The adsorption isotherms were carried out to indicate how the adsorbent will adsorb the solute, the degree of purification obtained after the process and the calibration of the maximum amount of solute adsorbed, thereby making possible an investigation of the economical viability of the adsorbent. The adsorption equilibrium data obtained for the removal of the RBBR dye at different initial concentrations of dye by watermelon and green coconut are represented in Figure 7A and 7B.

Figure 7: Quantity adsorbed from the RBBR dye at equilibrium in watermelon (A) and coconut (B)

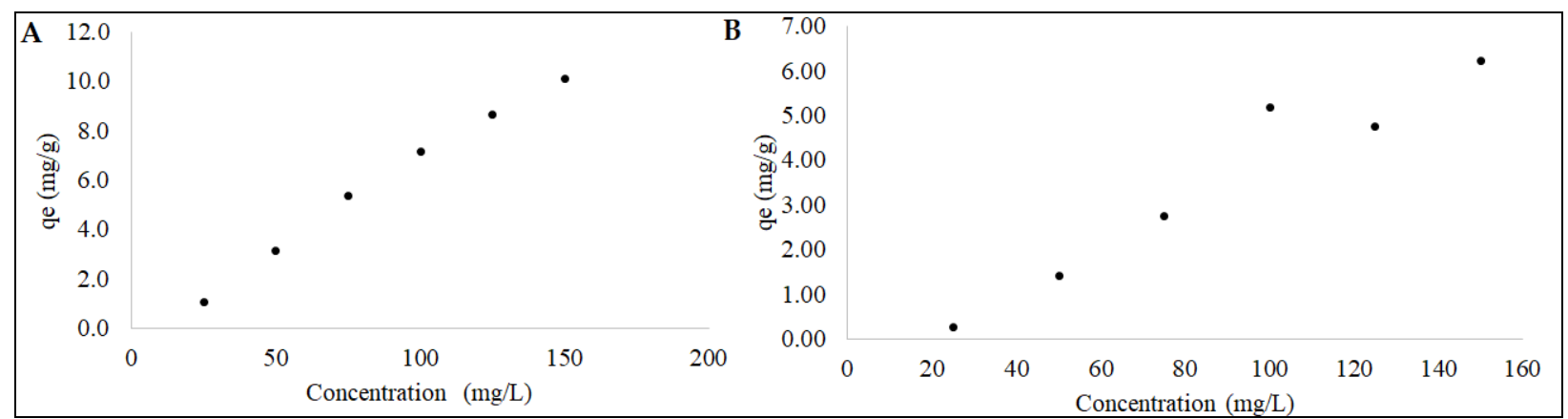

In the graphs, it can be observed that the watermelon possesses a greater capacity of adsorption of the dye when compared to the coconut, since in the same concentrations of solution $(\mathrm{mg} / \mathrm{L})$ at equilibrium, the watermelon adsorbed a greater amount of dye.

To assess the relationship between the equilibrium dye concentration $\left(C_{e}\right)$ and amount of RBBR at equilibrium $\left(\mathrm{q}_{\mathrm{e}}\right)$, the equilibrium data was analyzed with Langmuir and Freundlich isotherm models.

The Langmuir isotherm is the simplest theoretical model and it admits a monolayer adsorption on a surface with a finite number of identical active sites. The Langmuir adsorption isotherm is demonstrated by Equation 9 (RAHCHAMANl; MOUSAVI; BEHZAD, 2011). 
$q_{e}=\frac{q_{\max } K_{L} C_{e}}{1+K_{L} C_{e}}$

Where $C_{e}(\mathrm{mg} / \mathrm{L})$ and $\mathrm{q}_{\mathrm{e}}(\mathrm{mg} / \mathrm{g})$ are the concentration of adsorbate at equilibrium and the solid phase adsorbate concentration in equilibrium, respectively, $q_{\max }(\mathrm{mg} / \mathrm{g})$ is the maximum adsorption capacity corresponding to completemonolayer coverage onthe surface and $\mathrm{K}_{\mathrm{L}}(\mathrm{L} / \mathrm{mg})$ is the Langmuir isotherm constant.

The parameters calculated according to the Langmuir model are shown in Table 3. The Langmuir constant, $\mathrm{q}_{\max }$ which is the adsorption capacity in the watermelon and green coconut monolayers, were 29.412 and $4.847 \mathrm{mg} / \mathrm{g}$, respectively. This value of $q_{\max }$ is obtained for melanization when compared to the study by Lakshmipathy and Sarada (2015) with a native watermelon peel (243.9 mg / g) and methylene blue as adsorbate. In relation to the green coconut, the experimental value of $q_{\max }$ is twice that obtained by Isah et al. (2015) using activated charcoal based on coconut husk ( $q_{\max }$ of $\left.2.22 \mathrm{mg} / \mathrm{g}\right)$. The correlation coefficient obtained for the Langmuir isotherm using green coconut with adsorbent presented better adjustment for the equilibrium data.

The Freundlich isotherm is demonstrated by Equation 10, an empirical equation that admits heterogeneous adsorption due to the variety of active adsorption sites (CHIANG; WU, 2010; (RAHCHAMANI; MOUSAVI; BEHZAD, 2011).

$q_{e}=K_{F} C_{e}^{1 / n}$

Where: $q_{e}(\mathrm{mg} / \mathrm{g})$ is the solid phase adsorbate concentration in equilibrium, $\mathrm{K}_{\mathrm{F}}$ is the Freundlich constant, $C_{e}$ is the equilibrium liquid phase concentration $(\mathrm{mg} / \mathrm{L})$ and $1 / n$ is the heterogeneity factor, indicates the type of isotherm, if it is irreversible $(1 / n=$ 0 ), favorable $(0<1 / n<1)$ or unfavorable $(1 / n>1)$ (NUITHITIKUL; SRIKHUN; HIRUNPRADITKOON, 2010). The parameters calculated from the Freundlich model are presented in Table 3.

The results showed that the watermelon experimental data are in agreement with the Freundlich model, evidencing the value of $R^{2} 0.985$ (Table 3). The calculated 
values of $1 / n$ were considered in the range of $0<1 / n<1$ (Table 3), which indicated that the watermelon was suitable for the adsorption of the RBBR dye and that the adsorption process is favorable. The results show that the equilibrium data for the adsorption of RBBR dye onto the green coconut are best fitted with the model of Freundlich isotherm.

Table 3 - Isothermal parameters for RBBR adsorption in watermelon and green coconut.

\begin{tabular}{l|c|c|c}
\hline \multicolumn{1}{c|}{ Watermelon } & $\mathrm{q}_{\max }(\mathrm{mg} / \mathrm{g})$ & $\mathrm{K}_{\mathrm{L}}\left(\mathrm{min}^{-1}\right)$ & $\mathrm{R}^{2}$ \\
\hline Langmuir & 29.412 & 9.536 & 0.942 \\
\hline Freundlich & $\mathrm{K}_{\mathrm{F}}$ & $\mathrm{n}$ & $\mathrm{R}^{2}$ \\
\hline
\end{tabular}

\begin{tabular}{l|c|c|c}
\hline Green coconut & $\mathrm{q}_{\max }(\mathrm{mg} / \mathrm{g})$ & $\mathrm{K}_{\mathrm{L}}\left(\mathrm{min}^{-1}\right)$ & $\mathrm{R}^{2}$ \\
\hline Langmuir & 4.847 & 0.151 & 0.999 \\
\hline & $\mathrm{K}_{\mathrm{F}}$ & $\mathrm{n}$ & $\mathrm{R}^{2}$ \\
\hline Freundlich & 0.007 & 0.655 & 0.977 \\
\hline
\end{tabular}

\section{Conclusion}

Coconut and watermelon fibers were shown to be highly efficient as RBBR dye adsorbents. Comparing the coconut and watermelon fibers, the watermelon showed better results for adsorption, but both were positive for the adsorption process, with results of \% removal above $80 \%$. It is further emphasized the importance of using other dyes to analyze whether these fibers present a considerable amount of adsorption to other dyes.

The pseudo-second order model more accurately described the adsorption kinetics of reactive dye RBBR in watermelon and green coconut which reached equilibrium after 90 minutes. The Langmuir model was the one that best fit with the 
adsorption data in green coconut, and Freundlich model was the one that better adjusted for the watermelon, proving by the values of $R^{2}$. Finally, the ecological importance of the use of watermelon in wastewater treatment with the adsorption method is highlighted, since there is a great amount of organic waste of this fruit being little studied.

\section{Acknowledgments}

The authors would like to thank DYSTAR for the supply of RBBR dye and the Federal Institute of Santa Catarina (IFSC) - Jaraguá do Sul Campus for the infrastructure provided.

\section{References}

AWUAL, M. R.; HASAN, M.; IHARA, T.; YAITA T. Mesoporous silica based novel conjugate adsorbent for efficient selenium (IV) detection and removal from water. Microporous And Mesoporous Materials, v. 197, p.331-338, 2014.

BAŞ, D.; BOYACl, I.H. Modeling and optimization I: Usability of response surface methodology. Journal Food Engineering, v. 78, p. 836-845, 2007.

CHIANG, Y.; WU, P. Adsorption equilibrium of sulfur hexafluoride on multi-walled carbon nanotubes. Journal of Hazardous Materials, v.178 p.729-738, 2010.

CHINOUNE, K.; BENTALEB, K.; BOUBERKA, Z., NADIM, A.; MASCHKE, U. Adsorption of reactive dyes from aqueous solution by dirty bentonite. Applied Clay Science, v. 123, p.64-75, 2016.

CORRADINI, E .; ROSA, M. F., MACEDO, B. P ; PALADIN, P.D ; MATTOSO, L. H. C. Chemical composition, mechanical and thermal properties of fruits fiber of green coconut cultivars. Brazilian Journal of Fruticulture, Jaboticabal, v. 31, n. 3, p.837-846, 2009.

DALTIN, D. Study of the physico-chemical parameters of textile stamping with reactive dyes aiming the substitution of thickeners in the formulations of paints. Master's Dissertation, Institute of Chemistry, University of São Paulo, São Paulo, p.140, 1997. 
DASTKHOON, M.; GHAEDI, M,; ASFARAM, A.; GOUDARZI, A.; LANGROODI, S. M.; AGARWAL, S.; GUPTA, V. K. Ultrasound assisted adsorption of malachite green dye onto ZnS: Cu-NP-AC. Separation and Purification Technology, [s.I.], v. 156, p.780-788, 2015.

FERNANDES, A. C. P .; DA CUNHA, D. V .; PEREIRA, J.R.R., R ;; GUIMARÃES, T. A. P. S .; DE SOUSA, V. L. Adsorption of textile effluents: Treatment of effluents from the textile industry by adsorption on low cost materials. Project report. Faculty of Engineering of University of Porto, 2010.

FURLAN, F. R. Evaluation of the efficiency of the coagulation-flocculation process and adsorption in the treatment of textile effluents. $151 \mathrm{f}$. Dissertation (Master degree) Course of Chemical Engineering, Department of Chemical Engineering and Food Engineering, Federal University of Santa Catarina, Florianópolis, 2008.

HO, Y. S.; MCKAY, G. Pseudo-second order model for sorption processes. Process biochemistry, v. 34, n. 5, p.451-465, 1999.

HOSSEINI-BANDEGHARAEI, A.; HOSSEINI, M. S.; SARW-GHADI, M.; ZOWGHI, S.; HOSSEINIA, E.; HOSSEINI-BANDEGHARAEI, $H$. Kinetics, equilibrium and thermodynamic study of $\mathrm{Cr}(\mathrm{VI})$ sorption into toluidine blue o impregnated XAD-7 resin beads and its application for the treatment of wastewaters containing $\operatorname{Cr}(\mathrm{VI})$. Chemical Engineering Journal v.160 p.190-198, 2010.

ISAH, U. A.; ABDULRAHEEM, G.; ABDULLAHI, M.; BALA, S. Kinetics, equilibrium and thermodynamics studies of C.I. Reactive Blue 19 dye adsorption on coconut shell based activated carbon. International Biodeterioration \& Biodegradation, [s.l.], v. 102, p.265-273, 2015.

LAKSHMIPATHY, R.; SARADA, N. C. Methylene blue adsorption onto native watermelon rind: batch and fixed bed column studies. Desalination And Water Treatment, [s.I.], v. 57, n. 23, p.10632-10645, 2015.

NUITHITIKUL, K.; SRIKHUN, S.; HIRUNPRADITKOON, S. Kinetics and equilibrium adsorption of Basic Green 4 dye on activated carbon derived from durian peel: Effects of pyrolysis and post-treatment conditions. Journal of Hazardous Materials, v.41, n. 5, p.591-598, 2010.

MAFRA, M. R.; MAFRA, L. I.; ZUIM, D. R.; VASQUES, É. C.; FERREIRA, M. A. Adsorption of Remazol Brilliant Blue on an Orange Peel Adsorbent. Brazilian Journal of Chemical Engineering, Curitiba, v. 30, n. 3, p.657-665, 2013. 
RAHCHAMANI, J.; MOUSAVI, H.Z.; BEHZAD, M. Adsorption of methyl violet from aqueous solution by polyacrylamide as an adsorbent: Isotherm and kinetic studies. Desalination. v.267 p.256-260, 2011.

RAINERT, K. T.; NUNES, H. Equilibrium, kinetic and thermodynamic studies on the removal of reactive dye RBBR using discarded SBS paperboard coated with pet as an adsorbent. Desalination And Water Treatment, [s.I.], v. 86, p.203-212. Desalination Publications, 2017.

SILVA, T. L.; RONIX, A.; PEZOTI, O.; SOUZA, L. S.; LEANDRO, P. K. T.; BEDIN, K. C.; BELTRAME, K. K.; CAZETTA, A. L.; ALMEIDA, V. C. Mesoporous activated carbon from industrial laundry sewage sludge: Adsorption studies of reactive dye Remazol Brilliant Blue R. Chemical Engineering Journal, [s.I.], v. 303, p.467-476, 2016.

UGURLU, M.; KARAOGLU, H. Adsorption of ammonium from an aqueous solution by fly ash and sepiolite: Isotherm, kinetic and thermodynamic analysis. Microporous and Mesoporous Materials, v.139 p.173-178, 2011. 